\title{
Large-scale, hypervelocity, high-fidelity interceptor lethality development in AEDC's range $G$
}

\author{
D. Carver, L.L. Campbell*, B. Roebuck \\ 678 Second Street, Arnold Air Force Base, Tennessee 37389-4401, USA
}

\section{A R T I C L E I N F O}

\section{Article history:}

Received 7 May 2007

Accepted 6 June 2008

Available online 31 July 2008

\section{Keywords:}

AEDC

Range G

LGG

High-fidelity projectile

HVIS

\begin{abstract}
A B S T R A C T
The hypervelocity ballistic range $G$ at the Arnold Engineering Development Center (AEDC) is extensively used to conduct kinetic energy lethality tests for the Missile Defense Agency (MDA). Over the years, AEDC has continuously responded to the lethality test and evaluation requirements of Ballistic Missile Defense Systems (BMDS) at hypervelocity intercept conditions. Projectiles launched from two-stage light-gas guns experience acceleration loads that are typically orders of magnitude greater than those of the actual missile defense system. These acceleration loads drive design compromises in the projectiles' geometry and mass-density distribution necessary to survive the launch environment. A "high-fidelity" projectile with the proper geometry and mass-density distribution would provide a more representative simulation of the flight vehicle kinetic energy release at impact. Prior to the current upgrades, the range $G$ facility provided the capability to launch large projectiles [8-in. (203-mm) diameter] with weights up to $12 \mathrm{~kg}$ at launch velocities up to $4 \mathrm{~km} / \mathrm{s}$ but at acceleration loads near $40 \mathrm{~K}$ g's. Current upgrades provide for the capability to launch large-scale "higher fidelity" projectiles at the same high velocities but at half the $g$ loads. In addition, AEDC is developing a new technique for controlling the projectile pitch at the point of impact with a simulated target. These unique capabilities will make it possible to obtain more flight-representative lethality data in a ballistic range. This paper describes the upgraded capabilities now in place and continuing plans for further upgrades.
\end{abstract}

Published by Elsevier Ltd.

\section{Introduction}

Hit-to-kill (HTK) interceptor technology for ballistic missiles has been evolving for many years. Interceptor accuracy will ensure a hit, but not necessarily a "kill." It is critical in defense system evaluations to determine kill effectiveness (i.e., "lethality") of an interceptor. Intercept scenarios for ballistic missile defense systems include variation in impact angles, velocities, and interceptor pitch angles. The residual threat of a ballistic missile, after being hit, depends on the interceptor's design, mass, velocity, impact point, and impact orientation. Interceptor lethality can best be determined by controlled parametric tests, which are not feasible with flight testing.

Two types of test facilities have proven uniquely capable of providing lethality data: high-speed sled tracks, and light-gas guns (LGG). The premier U.S. facilities in each of these categories are the Holloman high-speed test track [1] and the hypervelocity ballistic range $G$ at the Arnold Engineering Development Center (AEDC) [2]. Each facility has its advantages, along with its limitations. The test track can accommodate full-scale interceptors, but its velocity limit

\footnotetext{
* Corresponding author.

E-mail address: larry.campbell@arnold.af.mil (L.L. Campbell).
}

is about $2 \mathrm{~km} / \mathrm{s}$, and it is limited to atmospheric pressure conditions. Quarter-scale tests [ $84 \mathrm{~mm}$ (3.3 in.); $0.5 \mathrm{~kg}$ ] at velocities from 2 to $7 \mathrm{~km} / \mathrm{s}$ have been the typical regime for AEDC's range G. Recent improvements have extended the range capabilities to near-half-scale tests [203 mm (8 in.); $15 \mathrm{~kg}$ ] at velocities up to $4 \mathrm{~km} / \mathrm{s}$.

\subsection{Range $G$ - the nation's largest two-stage light-gas gun}

Since 1963 AEDC has conducted more than 7000 hypervelocity ballistic range shots in its hypervelocity range $\mathrm{G}$ facility. The range G launcher (Figs. 1 and 2) is a two-stage LLG that launches projectiles into a 10-ft (3-m)-diam, 929-ft (283-m)-long, instrumented tank. The environment within the tank can be maintained at pressures from 0.2 torr to 1.7 atmospheres.

The 3.3-in.-diam launch tube typically is used to support onefourth-scale testing (i.e., projectile and target are one-fourth the size of the full-scale system). As missiles have grown more complex, the fidelity of the simulations has become more important. As a result, in 1995 AEDC embarked on a development effort to provide an 8-in.-diam launcher that could test near full-scale missile systems. That upgrade was successfully completed and was reported on in the 47th ARA meeting, in 1996, at the Institut 


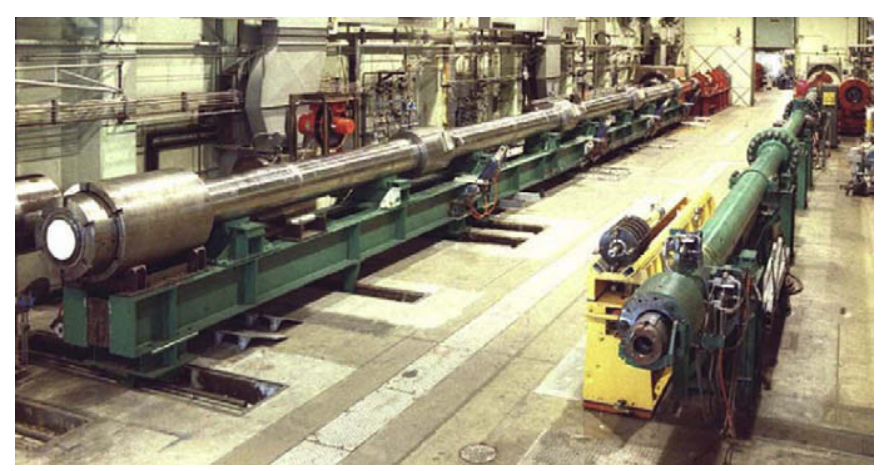

Fig. 1. AEDC range $G$ launcher room

Saint-Louis (ISL), in France. In 2004 an additional need surfaced that required still further improvements in the launching capabilities of the 8-in. launcher. To meet this need AEDC needed to reduce the peak $g$ loads of the 8 -in. launcher by half and double its throw weight.

In order to accomplish this task, the facility had to overcome several "limits." The first was the limitation on the amount of hydrogen that could be used in the launcher, and another was the blast tank length, which limited the length of barrel one could use as well as the tank's ability to safely contain the effluent of hydrogen from the launcher. Construction projects were initiated that increased the size of the blast tank (the area that absorbs the hydrogen expelled from the launcher) by 2.5 times and the length of the barrel by $60 \mathrm{ft}$ for a total of $192 \mathrm{ft}$. The extended $8 \mathrm{in}$. launcher is now operational and has successfully demonstrated an unprecedented capability to test very large high-fidelity missile simulations at hypervelocity speeds. Launcher capabilities are best shown graphically (Fig. 3) with launch velocity plotted vs. mass launched. Curves are shown for each existing barrel in the range $G$ launcher system.

\subsection{Typical lethality test procedure}

Test procedures for lethality assessment programs are typical of normal ballistic range impact testing [3] in that the projectiles are accelerated to the desired velocity in the launch tube, separated from the sabot (if sabot is required), and permitted to impact into the target while being monitored with an array of instrumentation to record projectile flight and target response. Projectiles that do not require a sabot can be guided by a unique track system from the launcher muzzle to within approximately a meter of the target. Use

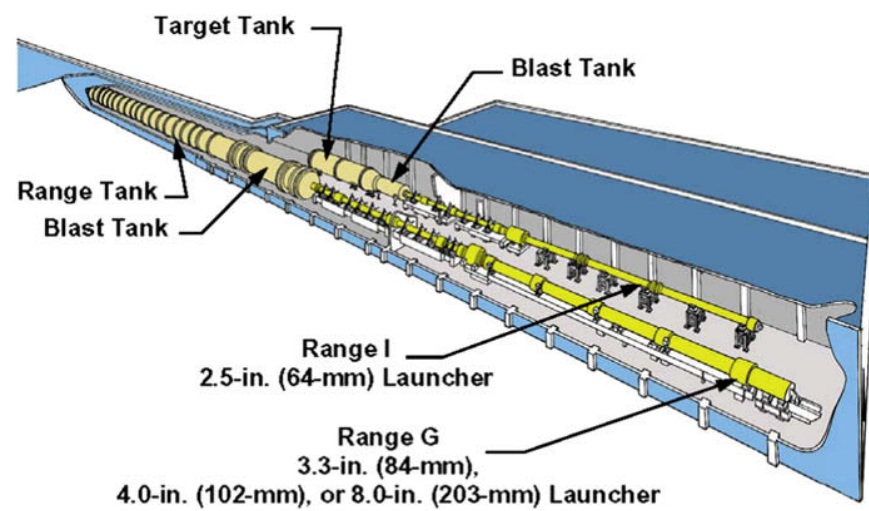

4.0-in. (102-mm), or 8.0-in. (203-mm) Launcher

Fig. 2. AEDC range G complex.

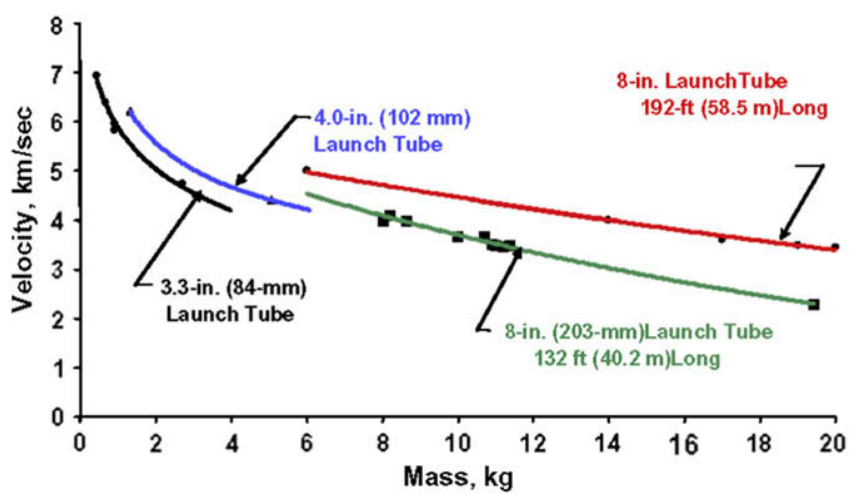

Fig. 3. AEDC range $G$ launcher capabilities.

of the track system provides excellent control of the projectile orientation and minimizes projectile dispersion. Projectile dispersion can be held within $3 \mathrm{~mm}$ of the desired impact point using the track capability. Fig. 4 represents a typical lethality test facility configuration.

During impact testing, target components and debris are accelerated to high velocities and can incur secondary damage if allowed to impact facility hardware. Secondary damage of critical target components or additional breakup of debris can drastically affect test results. For this reason, an arena (or box) consisting of a "soft-catch" material typically is constructed around the target (Fig. 4). The soft-catch materials are chosen on the basis of predicted target component velocity, strength, and installation cost [4].

\subsection{High-fidelity issues}

Projectile (interceptor) and target (enemy warhead) design considerations must be accurately modeled in order to achieve accurate subscale testing. Important projectile design parameters include mass, density distribution, and $L / D$ ratio. Accurate scaled targets must duplicate the primary kill mechanisms found in fullscale targets [5].

The primary challenge in designing projectiles for G-range lethality testing is to develop a geometrically scaled projectile that matches the axial and radial mass distribution of the actual missile with sufficient fidelity, yet possesses adequate integrity to withstand the acceleration loads experienced during launch. Recent upgrades using 3-D finite element analysis software (ABAQUS Explicit) coupled with the AEDC launcher code provide a seamless design path that permits AEDC engineers to analyze proposed projectile designs in a simulation of the dynamic environment of launch. The analysis simulates stress wave propagation through the projectile body, characterizing stress concentrations by color schemes. With marginal areas identified, design changes are incorporated that minimize the probability of projectile failure during launch. Fig. 5 shows the predicted peak "von Mises" stress distributions for a proposed high-fidelity projectile launched in the 8 -in. gun. Included in the figure is the acceleration history during the launch cycle.

In spite of the improvements made in the modeling arena, there are still unknown loads that affect the model structure. These loads are produced by asymmetries in the launch tube system that cause wear on the bore-riding surfaces of the model and therefore cause balloting in the bore. Future plans entail continued development of hardened miniature telemetry systems that can be used to quantify these loads and incorporate them into the final element analysis (FEA).

One recent achievement has been to launch a $15-\mathrm{kg}$ package mass (medium-fidelity projectile enclosed in a sabot) at velocities 


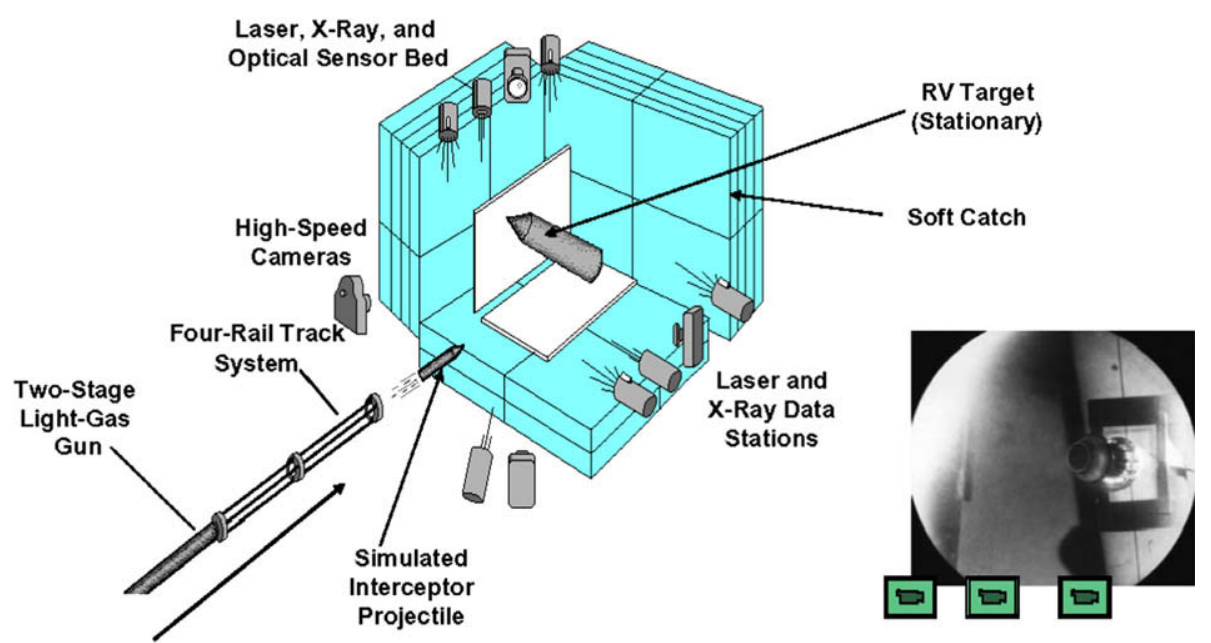

Fig. 4. Typical lethality test target arena.

in excess of $3.5 \mathrm{~km} / \mathrm{s}$ with $17 \mathrm{~K}$ g's peak acceleration loads. This feat was accomplished by extending the 8 -in.-diam launch tube by $60 \mathrm{ft}$ (to $192 \mathrm{ft}$, total length). Initial operational capability with the extended launch tube was demonstrated in August 2004. Nine shots have been completed to date, in efforts to establish the optimum gun cycle and successfully launch a high-fidelity projectile. Gun performance was first evaluated, and then projectile fidelity was increased. At present, a high-fidelity projectile has been launched successfully at $3.01 \mathrm{~km} / \mathrm{s}$.

Finding a "soft launch" cycle has proved to be a daunting task for the fragile high-fidelity projectile presently under consideration. AEDC has established a parametric solver for its vintage launcher code that examines thousands of gun cycles in an effort to find the optimum cycle. AEDC is currently updating its launcher code via a contract with Battelle Memorial Institute. The new, improved code will provide more accurate modeling of the basic physics, include a parametric solver to determine the optimum soft launch cycle, and provide a graphical user interface. The goal is the "softest" launch that does not exceed gun pressure limits. The gun cycle thus determined is used to define the base pressure history for a finite element analysis solution (ABAQUS Explicit). Maximum stresses and deflections defined from the ABAQUS Explicit solutions are reviewed, and possible failure areas noted; then the finite element model is refined, and the analysis is repeated until an acceptable configuration is determined.

A 6 -in. base diameter, 40-percent-scale (5- to 6-kg) projectile that replicates nearly all aspects of a typical interceptor has been tested at velocities up to $3 \mathrm{~km} / \mathrm{s}$ (Fig. 6). A load-distributing sabot is essential for launch of a high-fidelity projectile of this type. With the extended (192-ft long) barrel it should be possible to launch this projectile at $3.5 \mathrm{~km} / \mathrm{s}$.

\subsection{Interceptor pitch angle}

An HTK interceptor will not always hit its target head on. The effect of interceptor pitch angle on lethality must therefore be evaluated. AEDC has experimented with different pitching techniques, but because of the control issues has decided to rely on the "gas-jet technique."

The gas-jet technique produces projectile pitch through the use of a radial jet. The technique [6] was initially demonstrated using a gas reservoir designed into the projectile; however, higher pitch angles and increased fidelity can be achieved with a gas generator (thruster motor). Initial demonstration tests with a thruster motor have been completed. The gas-jet pitch inducement technique, as illustrated in Fig. 7, uses the energy source supplied by either a gas

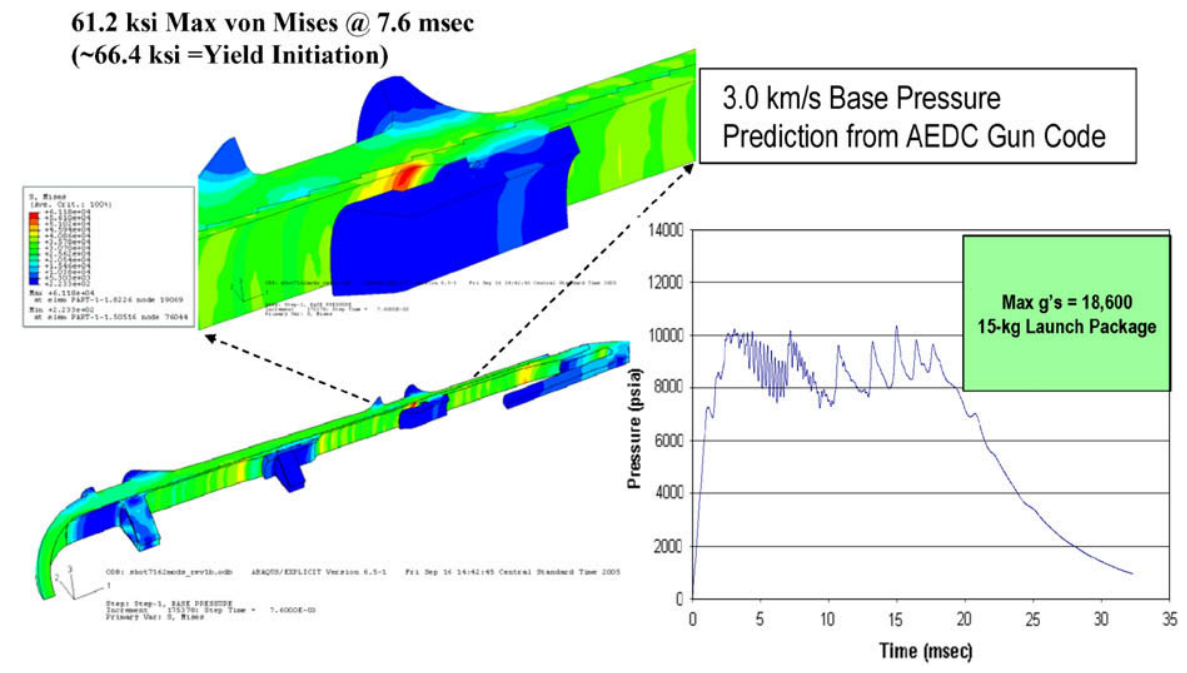

Fig. 5. Predicted stresses for a conceptual high-fidelity projectile launched at $3.0 \mathrm{~km} / \mathrm{s}$. 

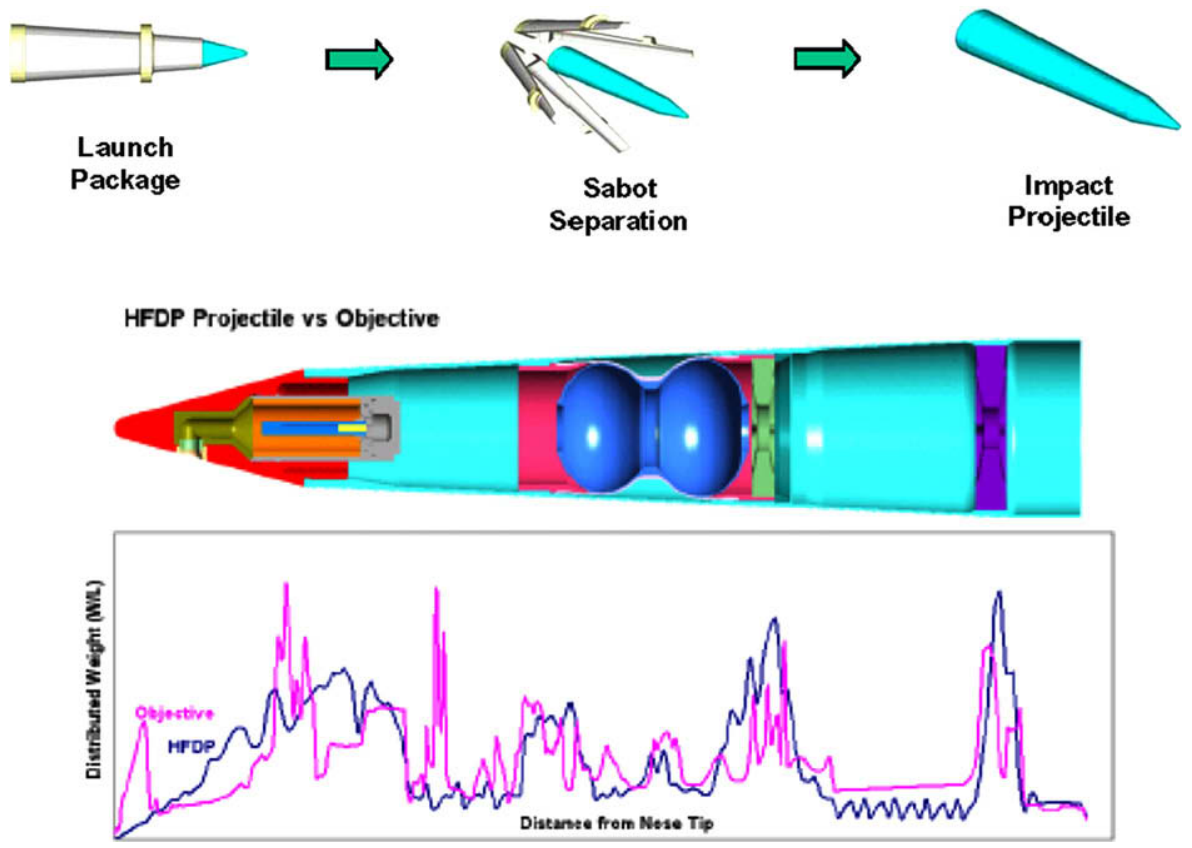

Fig. 6. Forty-percent-scale interceptor high-fidelity projectile.

reservoir or a gas generator. In each case the launch acceleration loads are used to initiate the gas release. The gas generator will produce higher pitching moments, and the projectile can be designed with higher fidelity than a gas reservoir configuration (gas reservoir requires pressure vessel design). Proper sizing of the gas generator will ensure that its residual energy is insignificant compared to the projectile kinetic energy. The Aviation and Missile Research, Development, and Engineering Center (AMRDEC), at the U.S. Army's Redstone Arsenal, in Huntsville, AL, is under contract to supply the gas generators that will produce up to $1400 \mathrm{lbf}$ of thrust for about $70 \mathrm{~ms}$.

Using a gas reservoir for pitch angle control has given excellent results: average pitch and yaw errors of $\pm 1.2^{\circ}$ and $\pm 3^{\circ}$, respectively. Use of a gas generator for angle control accuracy is expected to be comparable. Predicted pitch angles and fly-out distances are shown in Fig. 8 for a high-fidelity projectile that is launched at $4 \mathrm{~km} / \mathrm{s}$, with a gas generator that produces a peak thrust of $700 \mathrm{lbf}$. Flight distances of 255-325 ft (7899 $\mathrm{m}$ ) are required to reach an angle of $45^{\circ}$, depending on when the thruster is initiated. Doubling the thruster output to $1400 \mathrm{lbf}$ halves the travel distance required to achieve the same angle.

\subsection{Range and launcher upgrades}

In addition to the other improvements already mentioned, range $G$ has recently completed a military construction project to enlarge the range $G$ test area known as the Service Tunnel. The enlarged Service Tunnel will provide the space required to carry out launcher upgrades. The primary focus in the launcher upgrade portion of the project was to increase the launcher length; however, there are a number of supporting issues that require considerable effort.

Given below is a breakdown of the separate efforts that have recently been completed:

1. Facility hydrogen limit increased from 21 to $40 \mathrm{lb}$.

2. Eight-inch barrel length extended from 132 to $192 \mathrm{ft}$.

3. Blast tank bulkhead relocated.

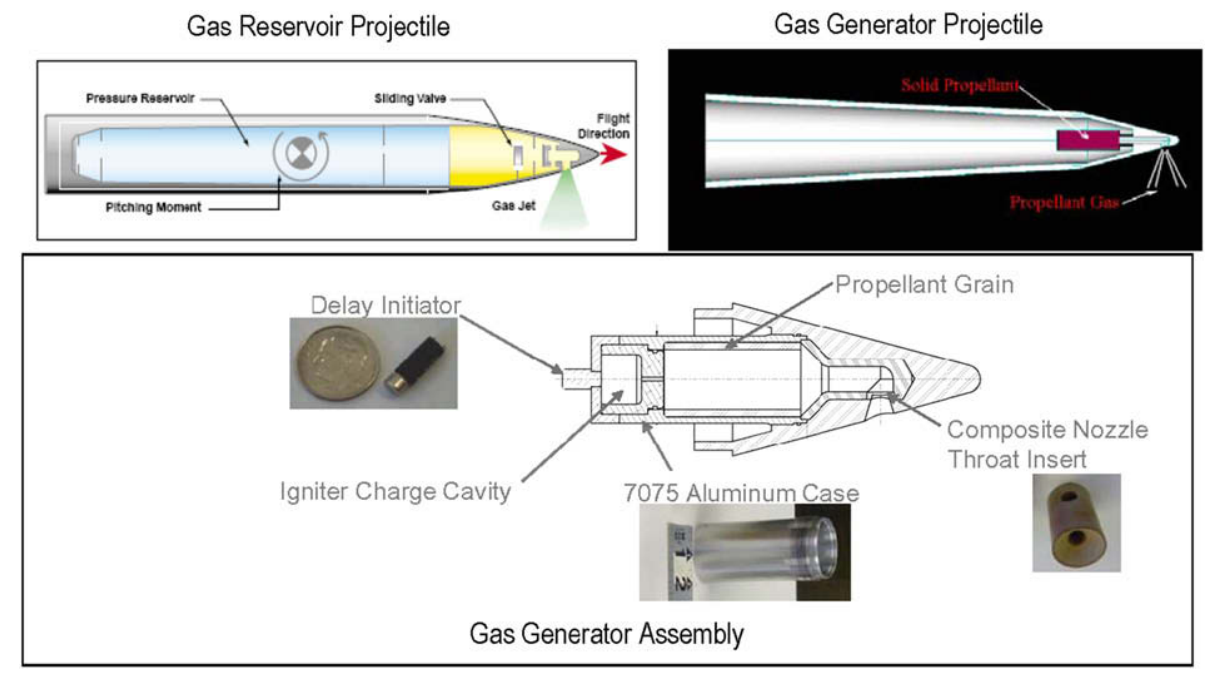

Fig. 7. Gas-jet projectile pitch technique. 

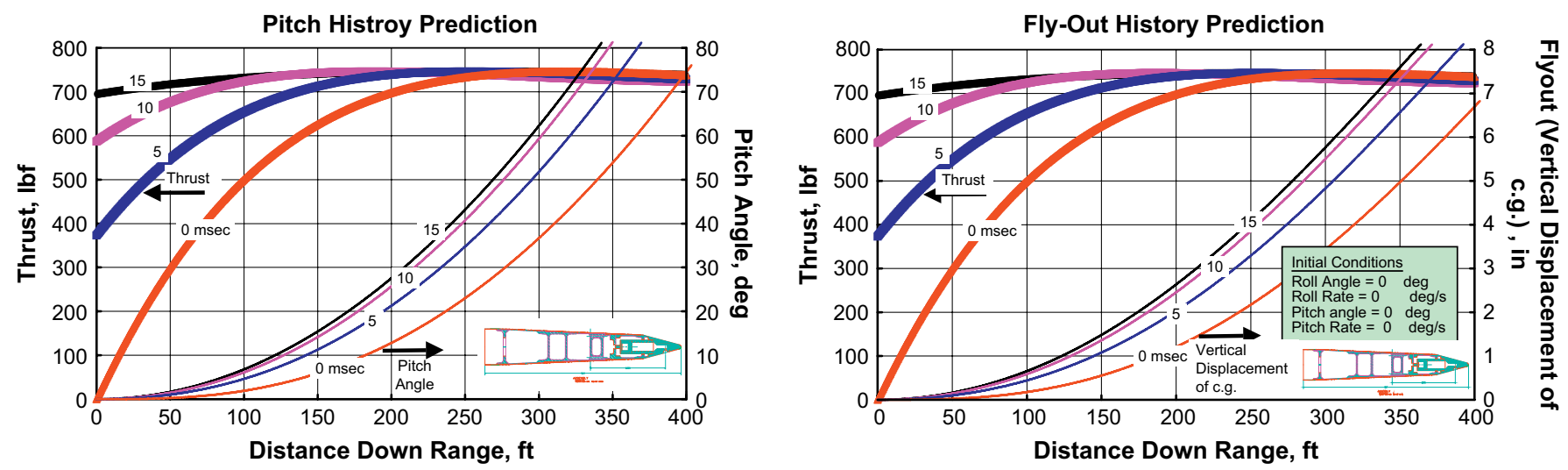

Note: The graphs represent the performance of a $12 \mathrm{lbm}(5.5 \mathrm{~kg})$ Projectile launched at 4 $\mathrm{km} / \mathrm{s}$, with a thruster motor that generates $\sim 700 \mathrm{lbf}(3100$ Newton). The thruster motor can be initiated at muzzle exit $(0 \mathrm{msec})$ or up to $15 \mathrm{msec}$ before muzzle exit to vary flyout angles at specified range distances

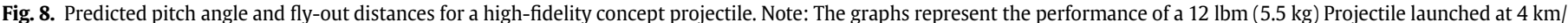

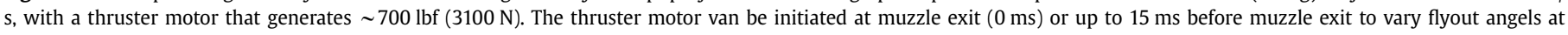
specified range distances.

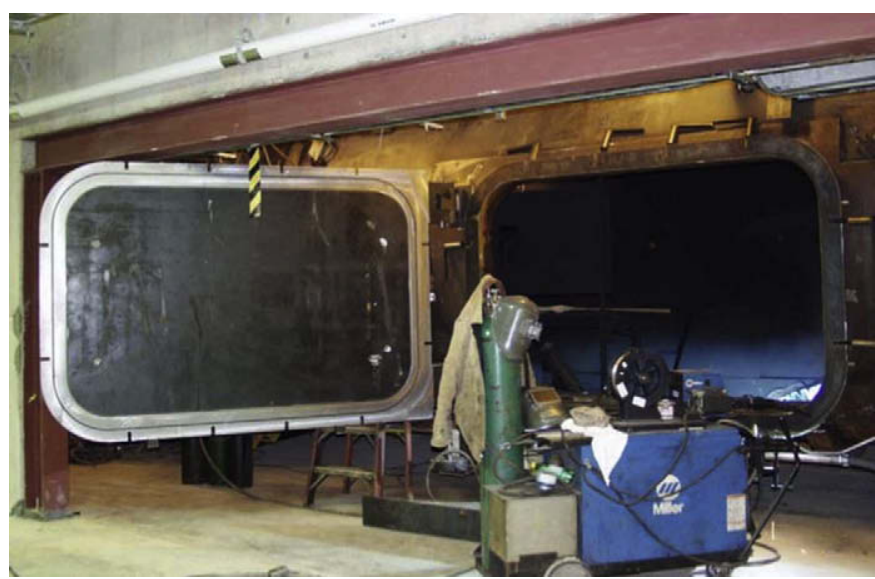

Fig. 9. Large target access door.

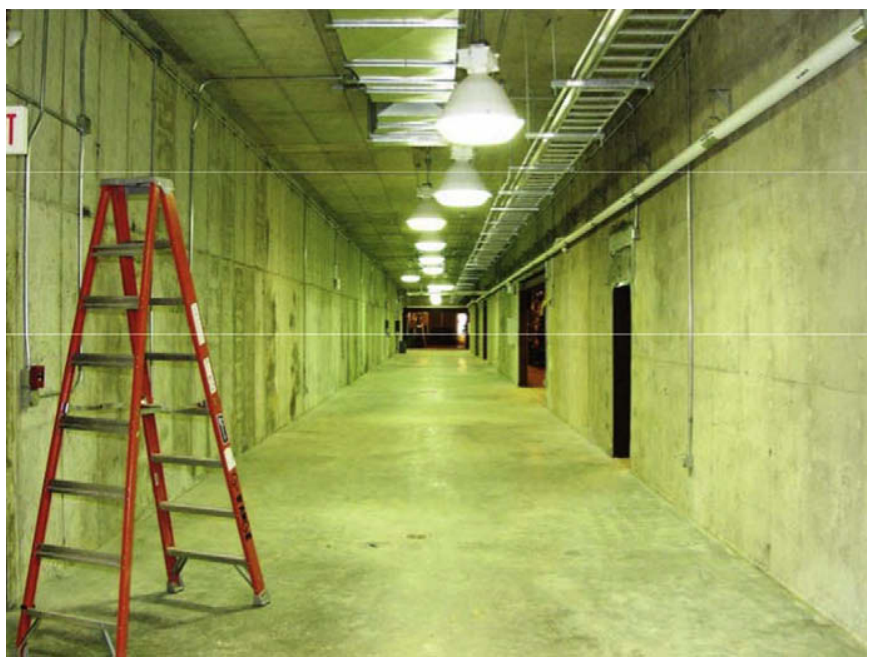

Fig. 10. Service tunnel addition.
4. Additional large range access door installed (Fig. 9).

5. Service tunnel widened by $15 \mathrm{ft}$ for $200 \mathrm{ft}$ of tunnel length (Fig. 10).

6. Ramp access provided to the sub-grade service tunnel area (Fig. 11).

The range has also been upgraded within the past year with a suite of state-of-the-art data systems. These systems are listed below, along with their basic specifications.

1. A transient data system that consists of four 32-channel rollaround racks. Each channel has a maximum sample rate of $400 \mathrm{M}$ samples/s with $4 \mathrm{MB}$ of memory per channel.

2. A new time measurement system, which has 128 input channels with timing resolution of less than $0.1 \mu$ s.

3. A new velocity-independent event synchronizer (VIES) system, which has three 10 channel pulse generators (these generators activate systems based on a real-time velocity calculation) and 20 four-channel delay generators, which can be programmed with a fixed time delay.

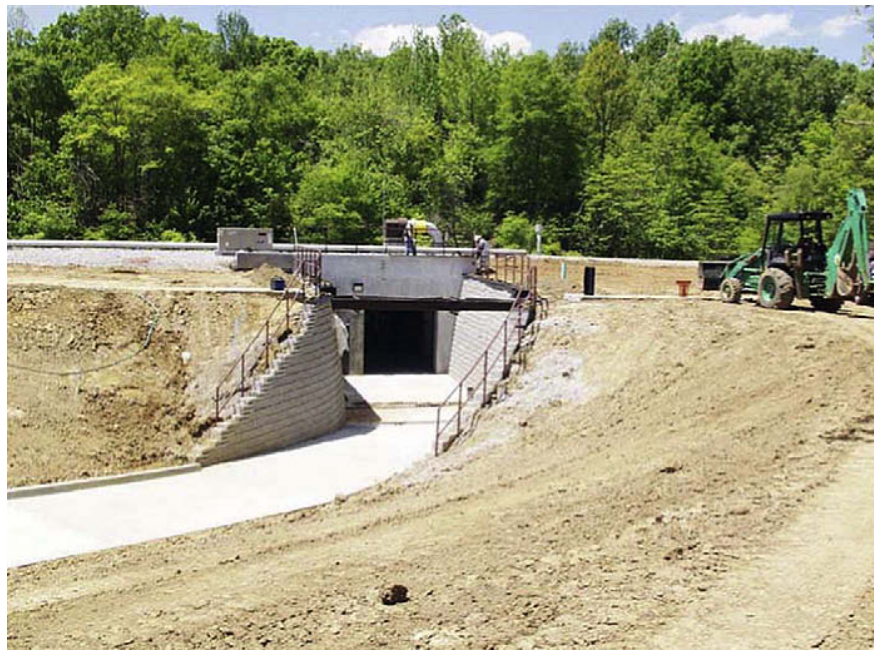

Fig. 11. Service tunnel entrance ramp. 
4. A new digital camera system, which includes one Phantom 9.0 camera, two Phantom 7.1 cameras, and six Stanford Computer Optics 4 Quik E 05A single-frame cameras.

5. A new test control sequencer countdown control system and a data-processing computer.

The launcher upgrade, the military construction project, and the new data systems are separate efforts that collectively will give range $G$ the unprecedented capability to launch high fidelity, largescale (40-50\%) projectiles to $4 \mathrm{~km} / \mathrm{s}$ and record all high-speed data from target impacts. It will also greatly increase flexibility for installing large targets in the range tank as well as removing postshot debris.

\section{Summary}

AEDC has continuously improved and modernized the range $G$ facility over the life cycle of the system in order to achieve and improve its now world-class testing capabilities. As testing requirements have evolved through new test programs and increased test complexity, the range $\mathrm{G}$ facility has adapted to these changes while continuing to provide the test environment capabilities desired by its many diverse customers. Current and planned future modifications to the facility continue to demonstrate the range $G$ personnel's strong desire to maintain the unique and robust testing capabilities for their customers. The facility and its technical experts continue to push the state-of-the art in groundbased testing for many key defense programs as well as research programs in areas of hypersonics and propulsion technology.

\section{References}

[1] Minto DW, Bosmajian N. Hypersonic test capabilities at the Holloman highspeed test track. Chapter 19. In: Lu FK, Marren DE, editors. Advanced hypersonic test facilities. AIAA progress in astronautics and aeronautics, vol. 198. Reston, VA: AIAA; 2002.

[2] Campbell LL. Increased launching capabilities at AEDC's range/track G. Chapter 20. In: Lu FK, Marren DE, editors. Advanced hypersonic test facilities. AIAA progress in astronautics and aeronautics, vol. 198. Reston, VA: AIAA; 2002.

[3] Young RP Jr. Expanded lethality test capabilities of the Arnold Engineering Development Center. In: Live fire test and evaluation conference, Livermore, CA; 1997.

[4] Wilbeck JS, Young RP Jr. Experience with techniques for characterizing debris generated during hypervelocity impact testing, paper no. AIAA-92-1586. In: AIAA Space Programs and Technologies Conference, Huntsville, AL; 1992.

[5] Vaught WH, Hunt RD, Hogg DM. The utility of subscale impact testing in defining theater missile defense weapon lethal effectiveness. In: Eighth multinational conference on theater missile defense, London, England; 1995.

[6] Jones GR, Bell LP. Pitch angle control of ballistic range projectiles. AIAA Paper No. 99-06-07; 1999. 